\title{
e-interview
}

\section{Louis Appleby}

Louis Appleby is England's Mental Health Czar and Professor of Psychiatry at the University of Manchester. He chairs the Mental Health Taskforce, set up to implement the NHS Plan. He is also Director of the National Confidential Inquiry into Suicide and Homicide by People with Mental Illness and an honorary Consultant Psychiatrist at the Manchester Mental Health and Social Care Trust. His principal research interests are suicide, self-harm and post-natal psychiatric disorders. He trained at the Maudsley Hospital, London.

If you were not a psychiatrist, what would you be?

A football journalist.

What has been the greatest impact of your profession on you personally?

I can no longer be a football journalist.

What are your interests outside of work?

Clarinet, Manchester United.

Who was your most influential trainer, and why?

Mike Matthews, an Edinburgh

Cardiologist. He treated patients with dignity and had a string of pithy phrases.

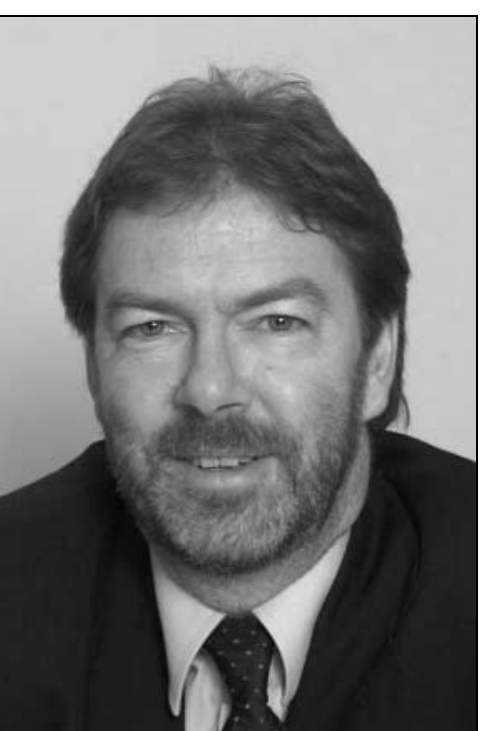

What do you least enjoy?

The train between Manchester and Leeds.

What is the most promising opportunity facing the profession? The chance to reshape itself to match its skills.

What is the greatest threat? Conservatism.

What single change would substantially improve quality of care?

Round the clock access to skilled care.

How would you entice more medical students into the profession?

Catch them early.

What is the most important advice you could offer to a new trainee?

Remember that small actions by you make a difference to other people's lives.

What job gave you the most useful training experience?

Nursing assistant, Bangour Village Hospital.

Which book has influenced you most? Stanley and the Women by Kingsley Amis.

What research publication has had the greatest influence on your work? Suicide by Emile Durkheim.

What part of your work gives you the most satisfaction?

Reports from patients that new initiatives are making a difference.
What is the main ethical problem that psychiatrists will face in the future? Assisted suicide.

How would you improve clinical psychiatric training?

Make it more community-based.

What single area of psychiatric research should be given priority? Dual diagnosis.

What single area of psychiatric practice is most in need of development? In-patient care. 